\title{
Diferença e educação a partir de um olhar queer
}

\author{
Teoria Queer: um aprendizado \\ pelas diferenças.
}

\author{
MISKOLCI, Richard.
}

Belo Horizonte: Autêntica Editora/UFPO, 2012. 80 p. (Série Cadernos da Diversidade, 6).

O trabalho do sociólogo Richard Miskolci poderia apontar, em princípio, para algo relativamente pouco original, uma vez que a aproximação entre a Teoria Queer e o campo da educação já vem anunciada em trabalhos como os de Louro, ${ }^{1}$ o que é apontado pelo próprio autor, que reconhece o papel fundamental que os profissionais da educação como Tomaz Tadeu da Silva tiveram no processo de difusão desse campo teórico no Brasil. Contudo, ao buscar lançar um olhar sociológico a partir da Teoria Queer sobre a dinâmica do processo educativo, em especial o escolar, ele retoma o diálogo existente entre as ciências sociais e a educação, que se tornou fortemente concentrado nas Faculdades de Educação desde a reforma universitária de 68 , como nos apontam Silva, ${ }^{2}$ Costa e Silva, ${ }^{3}$ e Martins e Weber, ${ }^{4}$ o que torna tal trabalho, no mínimo, singular.

Dotado de uma destreza teórica ímpar, e de uma grande sensibilidade intelectual, Miskolci consegue substanciar um livro que ao mesmo tempo atende anseios mais acadêmicos, sem, contudo, olvidar o público que deveria ser o principal desse tipo de produção: os docentes da educação básica. Há de se destacar que o autor, por um lado, já vinha contribuindo de forma enfática para o debate em torno da Teoria Queer no Brasil, como podemos perceber em trabalhos seus recentes, ${ }^{5}$ dentre outros, e por outro lado tem se aproximado do campo educacional, como na coletânea recente- mente organizada pelo sociólogo. ${ }^{\circ} \mathrm{O}$ livro aqui resenhado, aliás, é uma versão ampliada da Aula Magna proferida na abertura do curso de Educação para a Diversidade e Cidadania, em agosto de 2010, na Universidade Federal de Ouro Preto (UFOP).

Inicia-se de forma quase que autobiográfica em sua Introdução, remetendo às memórias escolares do próprio Miskolci, nas filas formadas no pátio da escola, onde "Começavam aí as 'brincadeiras', nas quais os meninos mais robustos empurravam os mais frágeis para a fila feminina, espaço desqualificado em si mesmo" (p. 9). Tais memórias situam-se num período singular da história brasileira, final da década de 1970, marcado por um processo educacional autoritário e violento. É nesta esteira que se chama aqui a atenção para o violento processo de normalização existente no âmbito educacional que o autor anuncia como o fio condutor do livro:

O objetivo que guia esta obra é o de refletir sobre os laços profundos entre educação e normalização social, entre a escola e os interesses biopolíticos, entre o sistema educacional e a imposição de modelos de como ser homem ou mulher, masculino ou feminino, hétero ou homossexual. Refletir para questionar e propor algo distinto, não normalizador ou compulsório, um educar fincado não em modelos e conteúdos que o precedem, mas antes na experiência mesma do aprender (p. 12).

Esta obra vai buscar, desse modo, um processo de estranhamento da escola, um estranhamento que leve a sua desnaturalização, e à percepção do movimento interno que a dinamiza e a possibilita produzir sujeitos a partir de determinados padrões.

No primeiro capítulo, "Origens históricas da Teoria Queer", o autor busca realizar uma retomada dos pressupostos de sua base teórica de análise, apontando que 
O que hoje chamamos de queer, em termos tanto políticos quanto teóricos, surgiu como um impulso crítico em relação à ordem sexual contemporânea, possivelmente associado à contracultura e às demandas daqueles que na década de 1960, eram chamados de novos movimentos sociais (p. 21)

Esses novos movimentos, que eram formados marcadamente por classes médias e altas, buscaram afirmar que o privado também era público, e mais que isso, que a desigualdade ia para além do econômico. Segundo o autor, a Teoria Queer teria se cristalizado na segunda metade da década de 1980, na época do surgimento da AIDS, que teria funcionado como um catalisador biopolítico. Miskolci nos chama a atenção para o fato de que a palavra "queer" em inglês é um xingamento, um palavrão, de modo que a ideia de uma Queer Nation refletiria justamente essa ideia, de uma nação abjetada. Assim, ele nos argumenta que a Teoria Queer surge como uma reação e resistência a um novo momento biopolítico instaurado pela aids.

Diferenciar-se-ia a Teoria Queer dos estudos gays por ir, justamente, na contramão de uma perspectiva que busca o mero "encaixe" em padrões, recusando valores morais violentos, enriquecendo, por um lado, os estudos gays e lésbicos com a sua perspectiva feminista através do conceito de gênero, e sofisticando o próprio feminismo, ampliando o seu alcance.

Miskolci chama a atenção ainda do leitor, em especial daqueles que são profissionais da educação, para a dinâmica da violência contra aqueles que adotam um gênero distinto do esperado, apontando que a questão é mais complexa que encontrar o modo correto de chamar alguém; é questionar o processo de classificação que gera o xingamento. Essa violência envolveria a todos: quem subjuga, a vítima, quem presencia... No espaço escolar isso se apresentaria de forma bastante forte, uma vez que, "Na escola, quer você seja a pessoa que sofre a injúria, é xingada, é humilhada; que seja a que ouve ou vê alguém ser maltratado dessa forma, é nessa situação da vergonha que descobre o que é a sexualidade" (p. 33).

No segundo capítulo, "Estranhamento e educação", o autor aponta para algo a que já nos referimos, que é a recepção que a Teoria Queer teve no âmbito educacional:

A acolhida brasileira da Teoria Queer na área de Educação pode estar ligada a uma compreensível sensibilidade crítica de nossas educadoras e educadores com relação às forças sociais que impõem, desde muito cedo modelos de comportamento, padrões de identidade e gramáticas morais aos estudantes, sobretudo crianças e jovens (p. 36)

Contudo, o autor também nos diz que a proposta queer vai para além de realizar um diálogo com os que normalmente são desqualificados do processo educacional, ou seja, a proposta queer iria para além do respeito à diferença.

Vale a pena ressaltar a digressão histórica em que ele aponta para o fato de que a escola foi, durante muito tempo, um local de normalização, um meio da biopolítica nos termos de Foucault. Destaca ainda uma palavra bastante na moda no debate público em torno da escolarização: o bullying, que se referiria ao caráter violento da socialização vivenciada na escola, negando a possibilidade de ser um fenômeno novo. Nas palavras de Miskolci

O bullying não foi inventado nos últimos anos o que mudou foi nossa sensibilidade com relação às formas de violência que ele expressa. A escola era partícipe do assédio moral de tal forma que, normalmente, a educação era bullying: você entrava e se enquadrava ( $p$. 38).

Esse caráter partícipe, em nossa interpretação, não é algo relegado ao passado apenas; pelo contrário, a escola continua a ser um local violento simbolicamente, excludente, ainda que o debate público em torno de tais processos tenha um impacto promissor em torno da alteração dessa realidade, de forma positiva

Outra categoria que Miskolci explora é a de abjeção, amplamente utilizada por teóricos como Judith Butler, cuja origem remete à Psicanálise. Segundo o autor,

O abjeto é algo pelo que alguém sente horror ou repulsa como se fosse poluidor ou impuro, a ponto de ser o contato com isso temido como contaminador e nauseante. [...] Quando alguém xinga alguém de algo, por exemplo, quando chama essa pessoa de 'sapatão' ou 'bicha', não está apenas dando um 'nome' para esse outro, está julgando essa pessoa e a classificando como objeto de nojo. A injúria classifica alguém como 'poluidora', como alguém de quem você quer distância por temer ser contaminado (p. 40)

A abjeção teria ganhado maior relevância na forma como pensamos as relações sociais a partir da experiência da AIDS. Derivaria do julgamento negativo em torno do homoerótico, 
mas, acima de tudo, do rompimento de padrões normativos; por isso homens gays que adotam um estilo de vida hegemônico sofreriam menos violência, e até corroborariam, de certa forma, com a heteronormatividade.

Outras categorias que o autor busca esclarecer são: heterossexismo, que se baseia na pressuposição de que todos são, ou deveriam ser, heterossexuais; heterossexualidade compulsória, que remeteria à imposição, como modelo, de relações amorosas ou sexuais entre pessoas do sexo oposto; e, por fim, a heteronormatividade, que seria a ordem sexual do presente, fundada no modelo heterossexual, familiar e reprodutivo. Uma consciência queer buscaria lançar um olhar insubordinado sobre essa realidade, sendo a escola um espaço privilegiado para tal operação. Este não seria um olhar da diversidade, categoria questionada pelo autor, uma vez que se aproximaria de uma perspectiva de tolerância. "Tolerar é muito diferente de reconhecer o Outro, de valorizá-lo em sua especificidade, e conviver com a diversidade também não quer dizer aceitá-la" (p. 46), o que manteria as relações de poder intocadas.

Para Miskolci, as correntes teóricas e políticas inspiradas pelas diferenças, que abarcam tanto a Teoria Queer quanto os Estudos Pós-Coloniais, seriam capazes de propor uma transformação da cultura a partir da desconstrução das normas e, sobretudo, das convenções culturais impostas. Devido a tanto, distinguir a questão da diversidade e a da diferença mostrar-se-ia fundamental para compreender mais claramente a proposta queer.

No terceiro e último capítulo, "Um aprendizado pelas diferenças", o autor busca sintetizar qual seria o grande desafio da educação em sua concepção, ou seja, a partir de um olhar queer:

Em uma perspectiva não normalizadora, educar seria uma atividade dialógica em que as experiências até hoje invisibilizadas, nãoreconhecidas ou, mais comumente, violentadas, passassem a ser incorporadas no cotidiano escolar, modificando a hierarquia entre quem educa e quem é educado $e$ buscando estabelecer mais simetria entre eles de forma a se passar da educação para um aprendizado relacional e transformador para ambos (p. 51).

O que o autor anseia é que a educação possa ser pensada como um veículo social de desconstrução de uma ordem histórica de desigualdade e injustiças, ainda que reconheça que, historicamente, nenhum outro espaço tenha sido tão amplamente utilizado enquanto espaço de normalização. Miskolci vislumbra um cenário de transformação cultural a partir da escola, o que se mostra como um cenário animador, considerando a recepção e o interesse atual da área da Educação brasileira nas questões das diferenças de gênero, raciais e sexuais. Isso estaria ligado ao momento histórico de expansão do sistema de ensino, ainda que caibam ressalvas neste debate, afinal

[...] é importante não 'trocar seis por meia dúzia' apenas buscando 'incluir' as diferentes expressões da (homo)sexualidade. Podemos fazer mais e melhor questionando o próprio binário hetero-homossexual (ou mesmo a tríade hetero-homo-bi) como um esquema rígido $e$ restrito que jamais abarcou toda a variedade de expressões afetivas e sexuais humanas ( $p$. 56)

Para elucidar essas questões, o autor recorre tanto ao exemplo do trabalho autoetnográfico de Giancarlo Cornejo intitulado "A guerra declarada contra $O$ menino afeminado", que consta em anexo no livro relatando sua experiência escolar, de controle em torno de sua identidade sexual, mas que também abarcou a própria família, em especial a figura da mãe, que passou também a ser objeto de controle e de condenação por parte da escola, quanto à experiência vivenciada pelo próprio Miskolci no curso de Gênero e Diversidade na Escola da UFSCar em 2009. Nesse curso ele relata que, como atividade final, foi pedido às educadoras que realizassem um projeto a ser aplicado em suas escolas, a partir do que aprenderam no curso - acontece que elas mesmas ainda se remetiam fortemente, em seus projetos, ao discurso da diversidade, da tolerância, o que seria insuficiente, uma vez que aprender a olhar para o mundo de forma não normalizadora exigiria mais que pensar famílias diversas, inclusão etc.

As demandas para os docentes são reconhecidamente enormes e assustadoras, o que decorreria do fato de que o medo e a vergonha do Outro também têm eco neles, nos educadores. A proposta queer buscaria, em vez de ensinar a reproduzir a experiência da abjeção, desenvolver um processo educacional capaz de ressignificar o estranho, o anormal, atuando como veículo de mudança social e de abertura para o futuro. 
Este pequeno trabalho de Richard Miskolci mostra-se como uma leitura indispensável aos educadores tanto em formação nas universidades, quanto já em salas de aula. Além disso, contribui para o próprio debate da Teoria Queer no Brasil, em especial no campo da educação, e para a discussão fomentada na interface entre as ciências sociais e a educação.

\section{Notas}

1 Guacira LOURO, 2001.

${ }^{2}$ Graziella SILVA, 2002

${ }^{3}$ Marcio COSTA e Graziella SILVA, 2003.

${ }^{4}$ Carlos MARTINS e Silke WEBER, 2010.

${ }^{5} \mathrm{MISKOLCl}, 2009,2011 \mathrm{a}, 2011 \mathrm{~b}$.

${ }^{6} \mathrm{MISKOLCl}, 2010$.

\section{Referências}

COSTA, Marcio; SILVA, Graziella Moraes Dias. "Amor e desprezo: o velho caso entre sociologia e educação no âmbito do GT-14". Revista Brasileira de Educação, v. 22, p. 101-120, 2003.

LOURO, Guacira Lopes. "Teoria queer: uma política pós-identitária para a educação". Revista Estudos Feministas, v. 9, n. 2, p. 541553, 2001

MARTINS, Carlos Benedito; WEBER, Silke. "Sociologia da Educação: democracia e cidadania". In MARTINS, Carlos Benedito; MARTINS, Heloiso
Helena T. de Souza (Orgs.). Horizontes das Ciências Sociais no Brasil: Sociologia. São Paulo: ANPOCS, 2010. v. 1. p. 131-201.

MISKOLCI, Richard. "A Teoria Queer e a Sociologia: o desafio de uma analítica da normalização". Sociologias, v. 21, p. 150-182, 2009.

(Org.). Marcas da diferença no ensino escolar. São Carlos: EdUFSCar, 2010.

"Não ao Sexo Rei: da estética da existência foucaultiana à política queer". In: SOUZA, Luiz Antônio Francisco de; SABATINE, Thiago Teixeira; MAGALHÃES, Boris Ribeiro de (Orgs.). Michel Foucault: sexualidade, corpo e direito. Marília, SP: Cultura Acadêmica Editora, 2011 a. v. 1. p. 47-68.

"Não somos, queremos: reflexões queer sobre a política sexual brasileira contemporânea". In: COLLING, Leandro (Org.). Stonewall 40 + o que no Brasil? Salvador: EDUFBA, $2011 \mathrm{~b}$ v. 1. p. 37-56.

SILVA, Graziella Moraes Dias. Sociologia da sociologia da educação: caminhos e desafios de uma policy science no Brasil (1920-79). Braganca Paulista, SP: Universidade São Francisco, 2002.

Amurabi Oliveira Universidade Federal de Alagoas 